\title{
METAPHORING AS SPEECH ACT: SOME HAPPINESS CONDITIONS FOR IMPLICIT SIMILES AND SIMPLE METAPHORS
}

\author{
DOROTHY MACK
}

Part of the problem in poetics is that terms like METAPHOR and SIMIEE are not well-defined; this article hopes to specify some of the necessary and sufficient conditions for metaphoring, but to begin with, these terms will be used traditionally:

A metaphor is something like he is a fox and he foxed us. A simile is something like he is like a fox and he is as canny as a fox.

However, the more general category, FIGURE of SPEECH, we refer to as METAPHORING. METAPHOR used as a verb emphasizes process rather than fixed entity, speech act rather than speech object. Metaphoring is something that speaker and hearer $d o$.

In an earlier paper (Lambert, 1970) we proposed some happiness conditions for explicit similes and assumed that they would apply to implicit similes and metaphors, even though no compared Predicate appears in their surface form. However, the same conditions will hold only if similes and metaphors are derived from the same deep or abstract structure. First we will restate the criteria for explicit similes; then show that if we posit the same deep structure for similes and metaphors, we can explain how we give them similar interpretations; and then we will explore the types of deletion and their effects.

\section{CRITERIA FOR EXPLICIT SIMLES}

Explicit similes, such as (1), state the quality being compared, though the hearer may construe others as well:

(1) That girl runs as swiftly as a gazelle (runs swiftly).

that is, the compared Predicate is present in the surface structure. Certain criteria involving the total speech act, such as speaker and 
hearer intention. and speaker and hearer knowledge of the language and cultural associations, will apply equally to implicil similes and metaphors - to all metaphoring - and will be discussed later. Other criteria insure that the comparison construction be well-formed according to rules of the grammar, to eliminate consideration of utterances such as:

(2) He sad I am.

(3) The table is as red as the idea (is red2).

(4) That girl 1 is as swift as that girl.

(5) That girl is like a girl/girls. (Banality)

The major criteria for explicit similes as sentence object types are two:

(A) AN Assertion and a Presupposition mlist be CONJONED - IN THAT ORDER - BY A COMPARISON MARKER. That is, a statement of fact, measurable and verifiable, must be conjoined with a metalingual statement of language use, a partial definition. Put still another way, the first Argument may be specified or not, but it cannot be generic; the second Argument must be generic, either an indefinite item designating a class, or else a class itself; the compared Predicate must be presupposed of the second Argument, but cannot be of the first.

(B) The Assertion must rifer proptrly; the Presupposition must MUST RE ACCURATE OR CORRICT.'

Criterion A eliminates the following constructions as explicit similes:

(6) That gurl rums swifly (A) $\sim$ That boy gazelle runs swiftly (A).

(7) The camella camelicamels run(s) swiftly (P) $\sim$ The gazelle/a gazelle/ gazelles run(s) suiftly (P).

(8) *Camels/gazelles/boys run suiftly (P) $\simeq$ That girl runs swifly (A).

(6) is the pattern for literal comparison $(A \simeq A) ;(7)$ is the pattern for metalingual comparison, or definition-via-comparison $(\mathbf{P} \simeq \mathbf{P})$; but $(8)$ is no pattern at all, indicating that similes are not reversible: the Assertion

1 Weinreich (1966) defines both Taulotogy and Banality, both important notions in rroper conjoining. A lexical item compared to itself is tautologous; compared to the class of which it is a member, banal. Another kind of locser tautology is formed when a specific instance of a Presupposition is conjoined to another Presupposition, as in (9). Zeugma. another type of figute, is very close to (3). based on a pun for the compared Predicate - a homophonous lexical item used in two different senses.

2 For the 'proper' ways an Assertion must refer, see Searle (1969: Ch. 4) or Reddy (1969): we will not discuss theories of reference in this paper. My 1970 paper listed five syntactic criteria which have been condensed to two, and rephrased in terms of presuppositions rather than 'permanent assigned features". 
must come first and the Presupposition second. Only ( 1 ) is the patiern for explicit simile $(A \sim P):$

(1') That girl rums swifl!! (A) $\sim$ A gazelle gazelles mu swiftly (B).

Criterion A also eliminates the Tautology

(9) ?This slegy is sad (T) $\simeq$ A funcral is sad (P).

since sad is presupposed of the first Argument. elegy.

Criterion B eliminates the following constructions as "happy or 'felicitous' explicit similes:

(10) ?That ginl runs swifily $(\mathrm{A}) \sim$ Boyshman beingsanimals rut swiftly (P).

(11) That girl ruts swifly (A) $\sim$ A smail runs swifly (5).

(12) ?That girl seeseats broathes stomps the grotnd suifty $(\mathrm{A}) \sim A$ gazelle sees cats breahes stomps the groumd swifly (?-).

(13) :That girl rums lazilyeagerlybreathlessly (A) $\sim$ A gazelle ruts lasilyeagerly; breathessly (F).

Presuppositions can be checked by negating them and disjoining them to the utterance in question with but (Fillmore, 1969):

(1") She is as swift as a gazelle, but gazelles aren't suift.

If the result is a contradictory construction, then the nonnegated presupposition, in this case, gazelles are swift, is Accerate. If. in contrast, the construction is not contradictory. the presupposition is not accurate. as is the case with those in (12) and (13):

(13a') She is as lezy as a gazelle, but gazelles aren't lazy. Etc.

Gazelles are neither lazy nor industrious; 'laziness' is not an attribute associated with gazelles by speakers of English. Similarly, "runs swiftly" is not associated with boys, human beings, and animals of (10), and the presuppositions in these constructions are InACCurate. Finally, if the disjoined construction is not only not contradictory, but is perfectly acceptable, then the presupposition is INCORRECT, as in (11):

(11') That girl is as swift as a snail, but snails aren't snift.

in that 'slowness' is presupposed of snails, rather than its opposite, 'swiftness", and the effect of (11) is ironic."

3 Paradox or oxymoron, and irony or sarcasm can be specified in terms of the following pattern: [Assertion $\simeq$ incorrect Presupposition]; see also (18). 
To be accurate, a presupposition check must take into account the whole second sentence. For example. (14) is unhappy because the compared Predicate is not presupposed of the second Argument, but (1.5) is acceptable:

(14) ?She is as green as a rock. (r) (rocks are neither green nor nongreen)

(15) She is as green as a rock in a sewer.

because a rock in a sewer is thought to be green; that is, the presupposition, "rocks in sewers are green (and covered with slime)", is accurate for speakers of English. Similarly, we can create other 'freshcuts' or original similes by ardding to an inaccurate or incorrect presupposition:

(16) ?She is as nervous as a cat/mun. (P) (cats are neither nervous nor calm; r uns are calm, placid, serene)

(17) She is as nervous as a longtailed car in a roomful of rocking chairs.

(18) She is as nervous as a pregnant mun in church.

\section{ARE SIMILES AND METAPHORS DERIVED FROM THE SAME DEEP STRUCTURE?}

The concept of 'deep' or 'abstract' or 'underlying' structure is itself metaphorical, useful for getting at what must occur for a speaker to utter sense and a hearer to understand it. It is a construct, a model for the vague notion, "what goes on in a speaker's head before and as he utters $\mathbf{S}$ ", a way of showing abstractly the necessary and sufficient conditions creating and giving meaning. However, the notion of deep structure can show only s.me of the happiness conditions for metaphoring; other conditions, part of the total speech act, will be discussed later.

The underlying structure of explicit similes is close to their surface form:

$\left.\left[\mathrm{ARG}_{1} \mathrm{PRED}_{1}\right](\mathrm{A}) \simeq \operatorname{COMP}_{\mathrm{ARG}} \mathrm{PRED}_{1}\right](\mathrm{P})$

with a comparison-conjoining rule which deletes the second instance of $\mathrm{PRED}_{1}$ and reorders the $\simeq$ COMP elements be and as/as. Or more simply, we can use predicate calculus terms (McCawley, 1968):

$$
\begin{array}{r}
P(X) \simeq P(Y) \rightarrow P(X \simeq Y) \text { given that } P(X) \text { is an Assertion \& } \\
P(Y) \text { is a Presupposition }
\end{array}
$$

If we posit the same deep structure for all metaphoring, we must posit 
four different types of deletion patterns to arrive at the quite different surface forms of implicit similes and metaphors.

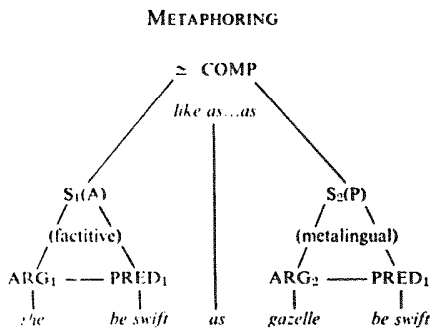

(19) She is as swift as a gazelle.

\subsection{ARGUMENT, COMPARATIVE and ARGUMENT,}

In implicit similes, the compared Predicate, PRED structure, resulting in the form:

$$
\left[A R G_{1}\right] \simeq \operatorname{COMP}\left[\mathrm{ARG}_{2}\right] \text { or } \mathrm{P}(\mathrm{X} \simeq \mathrm{Y}) \rightarrow(\mathrm{X} \simeq \mathrm{Y})
$$

so that not only is the compared Predicate irrecoverable, but also, so is the information that $S_{1}$ is an Assertion and $S_{2}$ a Presupposition:

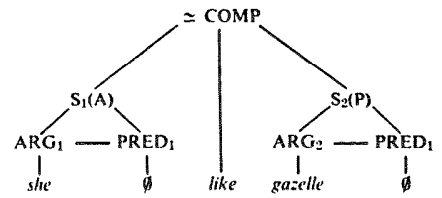

(20) She is like a gazelle. 


\subsection{ARGUMENT 1 and ARGUMENT 2}

In one type of metaphor, not only is the compared Predicate, PRED deleted, so is the $\simeq$ COMP as well:

$$
\left[A R G_{1}\right]:\left[A R G_{2}\right] \text { or } P(X \simeq Y) \rightarrow(X Y) \rightarrow Y(X)
$$

so that not only is the compared Predicate and Assertion/Presupposition information irrecoverable, but so is the information that $A R G_{1}$ is LIKE $\mathrm{ARG}_{2}$ - all notion of comparison is gone, and we must REINTERPRET $\mathrm{ARG}_{2}$ as a Predicate:

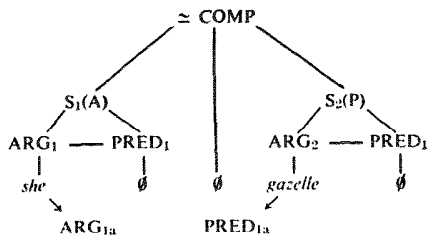

(21) She is a gazelle.

\subsection{ARGUMENT, PREDICATE 1 , COMPARATIVE, ARGUMENT 2 , and PREDICATE 2}

Not all similes and metaphors fit the pattern of $\left[A R G_{1} \simeq A R G_{2}\right]$ as in (20); sometimes it is MANNIR which is being compared, so that two Arguments and two Predicates occur in the deep structure:

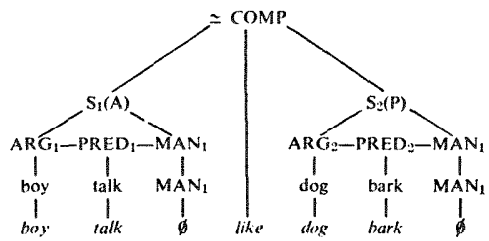

$[\mathrm{ARG} \text { PRED] }]_{1} \simeq$ COMP [ARG PRED] $]_{2}$ or $\mathrm{M}(\mathrm{P}, \mathrm{X}) \simeq \mathrm{M}(\mathrm{Q}, \mathrm{Y}) \rightarrow \mathrm{P}(\mathrm{X}) \simeq \mathrm{Q}(\mathrm{Y})$ 
(22) That boy talks like a dog barks."

\subsection{ARGUMENT 1 and PREDICATE2}

A much more radical effect occurs from metaphor deletion of $\mathrm{PRED}_{1}$ and $\mathrm{ARG}_{2}$ as well as the $\simeq$ COMP marker:

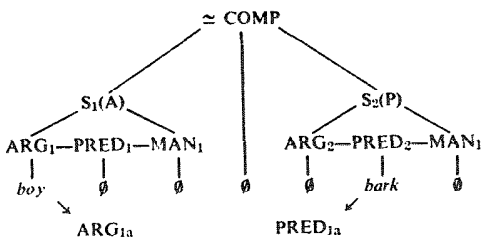

(23) That boy barks (at his parents).

Since all notion of comparison is gone, we must reinterpret PRED2 as a new Predicate, or $A R G_{1}$ as a new Argument:

$\left[\mathrm{ARG}_{1}\right] \Leftrightarrow[\mathrm{PRED}] \rightarrow \mathrm{ARG}+\mathrm{PRED}$ or $\mathrm{M}(\mathrm{P}, \mathrm{X}) \simeq \mathrm{M}(\mathrm{Q}, \mathrm{Y}) \rightarrow(\mathrm{X})(\mathrm{Q}) \rightarrow \mathrm{Q}(\mathrm{X})$ or $\mathrm{X}(\mathrm{Q})$

\section{REASONS FOR POSITING THE SAME DEEP STRUCTURE FOR ALL METAPHORING}

Positing the same deep structure for all metaphoring. even though simplicity would seem to argue against it, can help explain how we give metaphors and similes nonliteral interpretations; how we give them similar interpretations; how we can disambiguate them from literal assertions, literal comparisons, and metalingual comparisons; how we can give them seviral different metaphorical interpretations; and how we can distinguish them from other types of figure, such as metonymy and zeugma.

4 Less redundant siniles than 22) can be derived from this pattern: He is like a barking dog; He barks like a dog; etc. When this pattern is deleted even further, the remaining $A R G$ and $P$ 'RED can be reinterpreted as EITHER [ARG $P_{1} P_{1} D_{1}$ ] or [ARG PRED2), as shown witl: $(27 a \& b): M(P, X)=M(Q, Y) \rightarrow(X)(Y) \rightarrow X(Q)$ or $Q(X)$. 


\subsection{Ambiguities}

This $\simeq$ COMP deep structure is necessary to disambiguate the many confusing surface forms of implicit simile and metaphor; both forms masquerade as other types of constructions - simile appears to compare, while metaphor appears to equate.

3.11 This $\approx$ COMP deep structure is necessary to disambiguate LITERAL COMPARISON FROM SIMILE, as in (19), for which there are two different readings, $\left(19^{\prime} a\right)$ and $\left(19^{\prime} b\right)$; the different underlying structures reveal the difference in interpretations:

(19'a) That girl is as swift as a given gazelle, that one over there.

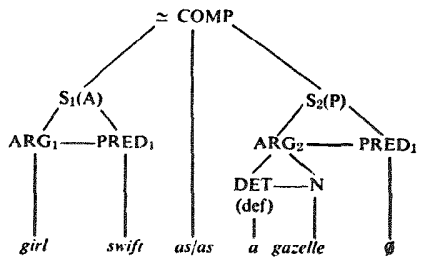

$\left(19^{\prime}\right.$ b) That girl is as swift as a gazelle, any gazelle, all gazelles, any member of the class, 'gazclle'.

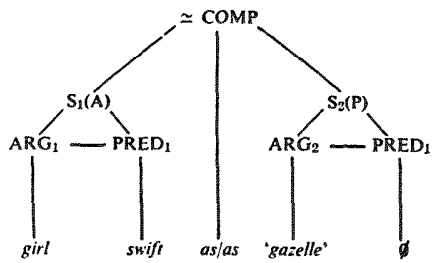

In the first version, the speaker has a definite gazelle in mind for the literal comparison; in the second, the speaker does not. The first illustrates 
Pattern $[A=A]$, as in $(6)$, for literal comparison; the second, Pattern $[A \simeq P]$, as in (1), for metaphoring.

3.12 This $=$ COMP deep structure is necessary to disambiguate siMILE from metalingual comparison, Pattern [P $\simeq$ P], as in (7) and (24a):

(24) A girl is as swift as a gazelle.

(24'a) A girl, any girl, all girls, any member of the class, 'girl, is as suift as a gazelle, any gazelle, all gazelles, any member of the class, 'gazelle'.

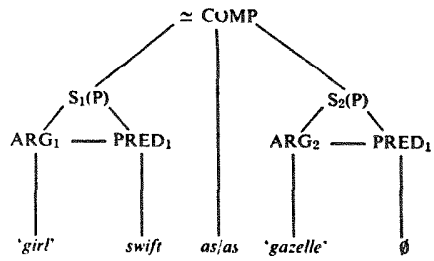

(24'b) A girl, a given girl, that one over there, is as suift as a gazelle, any gazelle, all gazelles, any member of the slass, 'gazelle'.

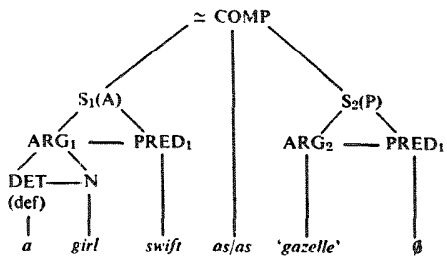

The first interpretation is an inaccurate metalingual comparison, inaccurate because the $S_{1}$ Presupposition, "girls are swift", is inaccurate - 
girls are neither 'swift' nor 'non-swift'. The second is an explicit simile, which appears to compare, but functions by attributing 'swiftness' to a specific girl via an extended Presupposition.

Such disambiguation can cnd THE MISCONCEPTION THAT SIMLLS ARE INTFNDED AND INTERPRETED AS LITERAL FACTUAL COMPARISONS. This popular confusion is continued by generative/transformational grammars which indicate metaphor as deviant, but similes as grammatical and normal. Yet simile consiructions in isolation from context are ambiguous, though the ambiguity in structure. often hidden by the determiner, $a$, has only rarely been noticed (Isenberg. 1963; Lambert 1969. 1970; Margolis, 1957).

Because similes are created by conjoining an Assertion and a Presupposition, they cannot be literal factual comparisons. Since the Presupposition is a partial definition, it cannot be verified as true or false. only 'correct/incorrect' or 'arhitrary/agrced-upon'; thus, similes, half-presuppositions, cannot be verified as true or false either. Similes masquerade as statements of fact, as verifable assertions about the world, but they are actually expressive personal assertions about the speaker's way of sceing - the speaker extends the scope of a Presupposition temporarily, for the duration of the speech act. Thus similes do not really cOMPARE relative degrees of 'swifness', they attribute presuppositions to other Arguments.

3.13 Thirdly, this $\approx$ COMP deep structure is necessary to disambiguate METAPHOR FROM LITERAL ASSIRTION (true or false), as in (21) and (23). Each of these utterances can be given two possible interpretations; now we can posit the different underlying structures which give rise to these different readings:

(21'a) She (human fentele) is the same as a gazelle. (21'b) She (human female) is like a gazelle in X-ness.
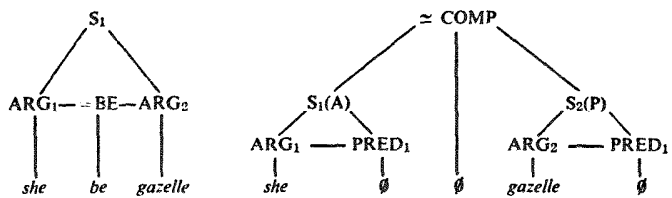
The first is a literal but false equation, ${ }^{5}$ which identifes rather than compares; it is reversible, as are all constructions with $=\mathrm{BE}$; the second compares deleted Predicates by means of metaphoring: he is an empty morph.

(23'a) The boy nem "woof- (23'b) The boy spoke abruptly and sharply, woof". etc.
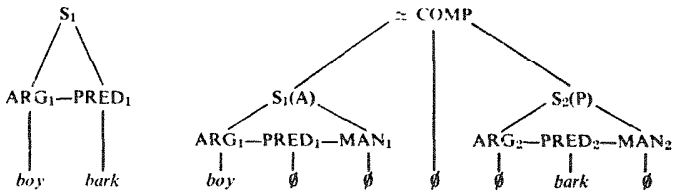

The first is a literal statement without comparison; the second compares deleted Manner items by means of metaphoring.

Again, disambiguation can end THE MISCONCEPTION THAT METAPHOR IS A ViOLATION OF THE RULES OF THE GRAMMAR. As we have seen, several types of metaphor seem to be perfectly grammatical nondeviant utterances in that they do not violate selectional restrictions, category rules, and other rules as presently stated in generative/transformational grammars:

(a) ambiguous utterances when considered in isolation from context, with at least two potential interpretations, like (2la \& b) and (23a \& b):

(b) uiterances with deictic or deleted referents, such as simple epithets (25) and pointing exclamations (26).

(25) Pig! (said of a man)

(26) Look at that gazelle! (pointing to a girl)

3.14 Finally, this $\simeq$ COMP deep structure is necessary to disambiguate TWO DIFFERENT METAPHORICAL INTERPRETATIONS, sUch as are possible for phrases like blossoms of smoke amd almost all instances of $\left[A \mathrm{KG}_{1} \simeq\right.$

5 Actually, (21) can be interpreted as a mistaken metalingual definition as welt, given the total speech act, if the speaker does not know the proper use of the word, gazelle, for instance. 
PRED 2 ] pattern. For example, (27) can be interpreted as either true full Personification or as Objectification:

(27) The table danced.

(27'a) The table came alive and danced. (Personification)

(27'b) The table figgled up and doun and moved around. (Objectification)

The true full Personification of $\left(27^{\prime} a\right)$ is more rare and restricted in genre - a Walt Disney version of "The Sorcerer"s Apprentice" in which a table does a dance; or ads; or nursery rhymes in which a dish runs away with a spoon hand in hand on sprouted legs. The difference in interpretations of (27) can be explained by the two different underlying structures and processes in metaphoring:

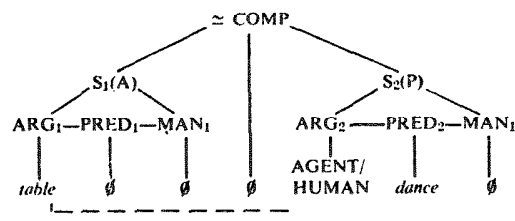

$\begin{array}{lll}\mathrm{ARG}_{23} \text { PRED } & \text { (Agent-promotion) }\end{array}$

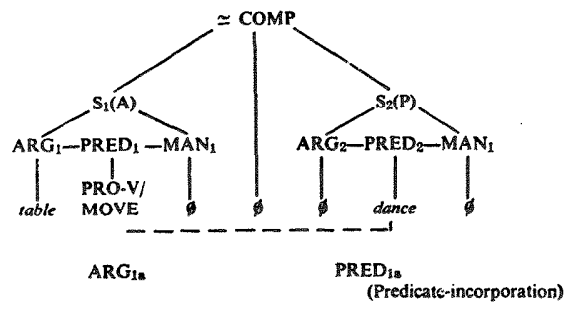

In the first interpretation, table is Personified: in the second, dance is 'de-personified' or 'Objectified'. However, in the total speech act, these 
distinctions are artificial; often the speaker intends us to accept BorH interpretations at the same time - this is one of the advantages of metaphoring - but in order to show how we can do this, we have had to separate the distinct interpretations.

Finally, disambiguation can end THE MISCONCEPTION THAT METAPHOR CAN BE ISOLATED IN A SINGLE PHRASE OR WORD. Critics have often disagreed as to which lexical item was the metaphor', not realizing that NO ONE WORD OR PHRASE can be identified as THE metaphor. With Dylan Thomas' phrase, a grief ago, Brooke-Rose (1958) considers ago the metaphor, while others (Levin, 1964) consider grief the metaphor. Or another Thomas' phrase, roots that clutch: Brooke-Rose considers roots "a simple Replacement noun metaphor", while others consider clutch the verb-metaphor. Out of context, both are right, since these phrases are as ambiguous as (27), and assertions about which lexical items is 'the metaphor' become futile.

\subsection{Comparison}

We know of no definition of metaphor which does not mention comparison. Yet no compared Predicate or compared Manner item is found in the surface structure of metaphors, whether like (21), or like (23) and (27). What will be the basis for metaphoring? And how is this to be expressed? And how will metaphor be distinguished from anomalous constructions which contain Arguments with no qualities in common? Without the notion of comparison in some deep or abstract structure, we will find it difficult to explain the non-equative, attributive function of metaphoring. We will also find it difficult to explain why certain odd constructions, such as (28):

(28) (The concept of) triangularity barks.

are interpreted as anomalous.

Comparison in the deep structure avoids THE MISCONCEPTION THAT METAPHORS DO NOT COMPARE, THEY EQUATE - somehow, without being false.

\subsection{Conjoining}

Again, we know of no definition of metaphor that does not mention two items being compared. Yet metaphors like (23) and (27) have no connectives in surface structure. How do these two 'items' get linked? 
Without conjoining in the deep structure to explain how metaphoring connects one part to another, we will have to posit some other function, such as "feature transfer" (Weinreich, 1966: Bickerton, 1969). The problem is to understand how feature transfer works - why here and not elsewhere? Weinreich is vague wher he writes of how it will function: "an accommodation" of iransferred "contradictory features" which will "construe entities out of contradictory features" which are "pre-coded in a language". His theory functions "more actively by transferring the feature from the verb to the nouns" in a deviant sentence. However, what kind of 'accommodation' occurs with metaphor. but not anomaly? "Feature transfer" or "feature projection" (Lambert, 1969) is a convenient notion. but without reference to a $\sim$ COMP deep structure, we do not comprehend how it would work in practice. This paper, rather than inventing a new linguistic linking process, uses the existing process and rules of conjoining, and specifies instead, THE PAR TIC ULAR KIND OF CONJOINING which results in metaphoring.

Conjoining in the deep structure avoids THE MISCONCEPTION THAT METAPHOR OPERATES IN SOME SPECIAL, ALYOST MYSTICAL FASHION "tension" (Wheelwright, 1962), "interaction" (Black, 1962), "accommodation" (Weinreich), or the uninformative notion. "simple replacement" (Brooke-Rose, 1958). Rather, metaphoring links in a regular but highly specific way.

\subsection{Presupposition}

Something about the relation of the compared Predicate to the second Argument is crucial to metaphoring; otherwise we will have some very odd or unhappy constructions, like (9) through (14). Yet most definitions do not even mention this aspect. And terms used by a few to grapple with this notion, such as "associated inherently with" (Weinreich) or "special attribute" (Bickerton), or "permanent assigned feature" (Lambert, 1970), lead into traps about the nature of language as well as to difficulties with the nature of lexical entries and the notion of 'features'. They identify but do not explain this crucial relationship.

Without a notion of Presupposition in the deep structure which is almost but not totally deleted in surface structure, we will have a hard time explaining why as green as a rock is odd but as green as a rock in a sewer is OK. Presupposition is essential to the study of metaphoring; not only can it explain unhappy constructions, it can explain the tautologous quality of explicit similes, and it can identify irony or sarcasm, 
paradox or oxymoron, tautology, and banality in nonliteral expressions.

Presupposition in the deep structure avoids THE MISCONCEPTION THAT MLTAPHOR MERELY "GNES X A NAME THAT BHENGS TO $Y$ '. ACcording to this inaccurate and incomplete notion. almost any anomaly can be given a metaphorical interpretation, such as (28). Rather, metaphoring is a highly specific, quite narrow phenomenon.

\subsection{Muliple Interpretation}

Deletion patterns from a common deep structure can explain how multiple interpretations of implicit similes and metaphors are pussible -at least six for (20) and more for (21) -... Whenever there is an irrecoterable Unspecitied Predicate. Indeed. it is diflicult to talk about what (21) means without mentioning attributes or qualitics of gazelles: yet these never appear in surface structure. Such Unspecified Predicates can be said to exist. since at laast one atspect must be found in common between the two Arguments being conjoined for the construction to be a wellformed comparison: an Unspeciticd Prelicate in a comnarison construction has at least one theoretical reading. This one theoretical reading provides the hasis for riddles such as "why is the sky like a table?" and many creativity exercises (Torrance. 1965) such as "how is a car like a spoon?"

Deletion patterns from a common dees structure avoids THE MISCONCEPTION THAT A METAPHOR HAS ONE MIANING AND THLS A LITERAL TERM CAN BE HOUND UNDERLYING; THE MLTAMHOR. Chomsky (1965) posits an underlying grammatical sentence parablel to a deviant one to explain how we interpret deviancy: similarly, some critics look for a literal" term "underlying" or 'behind' the metapher to explain how we interpret them as nonliteral. This position also assumes that all metaphoring is paraphrasable. What, is usually meant by 'literal term' is the deleted compared Predicate, such as swifi could he in (20) and (21).

Implicit similes and metaphors which are shortcuts" -... conventiona!ized expressions derived from formulas such as as green as grass or as patient as Job - may appear to have a "literal' term underlying them. However, this is simply that we have agreed-upon meanings: that Job represents patience rather than bad luck and that grass is always green. even though much of the year grass is brown."

6 But notice, we can say as untuck y as Job and as hrown as grass (deadgrass) equally acceptably - but they function as 'fresheuts" rather than "shortcuts', originals not formulas. 
However, for those implicit similes and metaphors which have a deleted compared Predicate not immediately recoverable by formula, a search for the 'literal term' or paraphrase will be elusive. For example, which is the literal term or paraphrase of (20) and (21)?

(a) that she runs quickly and lightly

(b) that she is shy

(c) that she is dainty and light-boned

(d) that she has big brown eyes and a long slender neck

(e) that she is dificult to catch

(f) or all of these - and so on.

Thus, contrary to Brooke-Rose (1958). Dylan Thomas' phrase, a grief ago, has no literal term 'underlying' grief - not day, not time, not while - but only a general Time-noun category indicated by cooccurrence with rigo, $(+$ Time $)$ and $[+$ Past $]$, and $a,[+$ Count $]$.

Because metaphoring creates a whole range of possible shared attributes, there is no point in paraphrasing or 'translating' a metaphor into literal statement to 'understand' it; this cannot be done accurately except with the simplest ideas or the most conventional formulas. Paraphrase is a useful heuristic device which does not ignore the main purpose of metaphoring: to create multiple-meaning.

\subsection{Degree of Deletion}

This $\simeq$ COMP deep structure can explain not only ambiguity and multiple interpretation, it can also show how deletion affects similes and metaphors differently; similes are said to be less 'forceful' or 'striking' or 'direct' than metaphors, though this is often a question of originality rather than form. However, metaphors do differ in interpretive 'force' - the deletions are so severe that they force a Reinterpretation of the remaining elements, either by Pattern $4.2,\left[A R G_{1} \approx A R G_{2}\right]$ as $\left[\mathrm{ARG}_{1 \mathrm{a}}+\mathrm{PRED}_{1 \mathrm{a}}\right]$; or by Pattern 4.4, $\left[\mathrm{ARG}_{1} \simeq \mathrm{PRED}_{2}\right]$ as $\left[\mathrm{ARG}_{1 \mathrm{a}}+\right.$ $\left.\mathrm{PRED}_{1 \mathrm{a}}\right]$ or $\left[\mathrm{ARG}_{2 \mathrm{a}}+\mathrm{PRED}_{2 \mathrm{a}}\right.$ ]. Because metaphors appear to equate, they seem more forceful; in effect, they become more open to multiple interpretations as more and more deep structure is deleted.

Degrees of deletion from a common deep structure can end THE MISCONCEPTION THAT THE DISTINCTION BETWEEN SIMILES AND METAPHORS IS CRUCial, RATHER than allomorphic. Brooke-Rose (1958) uses the presence of like or as (plus others, such as resemble) as a major criterion in winnowing examples of metaphor from other types of figure 
in prose and poetry. Other, such as Richards and Black, almost ignore the distinction. What Brooke-Rose seems to be getting at is another distinction, one made also by Weinreich (1966). that of modality. Both asscziate similes but not metaphors with some kind of counterfactual modality. Brooke-Rose counts the modal Predicate resemble as a similemarker, even though it may be used equally in literal comparison:

(29) This book resembles that one.

And Weinreich noted 'a non-linking effect' of like plus predicate nominat at certain times. leading one "to interpret the constructed semantic entity not literally, but with some qualification, such as suspension of belief about the truth of an assertion or a disclaimer of responsibitity for its truth ... by specal conjugational caterories (mocds, evidentials) or by 'sentence adverbials' (perhaps, cerrainly) ... and expressions indicating that semantic features are not to be taken licrally (so-called, like, or so) ... The copulative verb seem (like) also appears to function in the capacity of modalization, as do pseudo-transitive verbs like resemble $\mathrm{X}$ ("be $\mathrm{X}$ in appearance only')". However, like may or may not mark "literalness":

(30) This book is like that one.

Rather, it seems that modality is related to metaphoring, but it is not clear how; both similes and metaphors occur in modal constructions:

(31) There could I marvel my birthday away. (Thomas)

(32) l feel as if worms were crawling in my hones.

and outside of them. Some modals, such as seem and resemble, indicate non-equative constructions as do like and as, as well as the information, 'be in appearance only'; others indicate truth-suspending discourse. That is, modals can aid and abet metaphoring, but are not essential to it.

\subsection{Types of Metaphoring}

This $\sim$ COMP deep structure can explain the closeness in interpretation of certain similes and metaphors, such as (20) and (21), despite variant surface forms; without it we will find it difficult to relate the various kinds of metaphoring other than by presence or absence of surface markers, a criterion which is very misleading. Anyone who has had students blindly identify (33) and (34) as similes yet miss (35) and (36): 
(33) They like pomegranates but not figs.

(34) As far as I'm concerned, they can go.

(35) Her mind resembles a fig tree.

(36) Imagine this house is a well.

recognizes the thlacy of this narrow conzeption of simile form. Positing a common deep ? ructure for all metaphoring can end THE MISCONCEPTION THAT like AND as ARE NECESSARY AND SUFFICHENT MARKERS FOR SIMLLFS.

Rather, similes can occur in several can occur in several of the various forms of comparison - those indicated by the Predicates (some also modals) imagine, suppose, secm (like). look like, resemble, appear (to be), compare and similar:

(37) Her mind seems like/looks likelappears to be a fig tree.

(38) Shall I compare thee to a summer's day?

those indicated by the comparison-conjoining markers more/less... than and wer than:?

(39) She is swifter than a gazelle.

(40) He is more/less patient than Job.

and those indicated by the adjective suffixes $-l i k c,-i s h$, and sometimes a few others: ${ }^{8}$

(41) That pig-like/piggish man!

(42) He is feminine/starry-eyed.

\subsection{Types of Figure}

Deletion patterns from a common deep structure can not only relate different types of simile and metaphor, they can distinguish metonymy and other types of figure from metaphoring. For examp:s, MEtonyMY INVOLVES EMBEDDING AND SUBSTITUTION, rather than comparison and deletion:

7 Interestingly, superlative forms furn similes into metaphors: (39a) She is the swiftest gazelle illic swiftest of gazelics. or cise literal but false assertions. Literal comparisons deal with RELATIVE qualities; metaphoring with ABSOLUTES.

8 The adjectives in (42) are borderline cases; sfarryoyed can be derived from eyes like stars, or eyes made of stars, for example. 


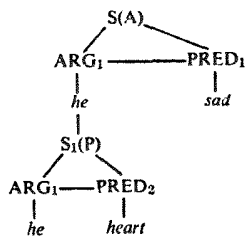

(43) His heor! is sad.

Full metonymy, which substitutes $P R E D_{2}$ for $A R G_{1}$, can be represented thus:

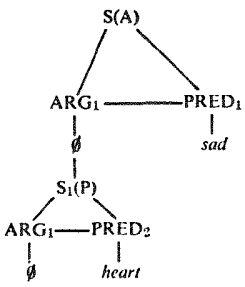

(44) Hearts are sad.

This wil! hold whether we have Body-part Metonymy or Attribute Metonymy - a part or quality substitutes for the whole Argument 1. Deep structure can also reveal similarities among figures: for example, both metonymy and metaphoring involve a combination of Assertion and Presupposition, but metonymy does this by embedding, not conjoining.

\subsection{Syntactic Criteria}

Reddy (1969) argues that there can be no general syntactic criterion for metaphor; we assert that this is true only if dealing with surface forms. 
Deep structure allows us to posit one semantic (proper Assertion; correct Presupposition) and two or three syntactic criteria ( $A \sim P$ pattern: correct conjoining: correct deletion) necessary for metisphoting. These are necessary but not sufficient conditions for the speech act of metaphoring. Although we could use other aspects of the speech act, such as speaker and hearer intention. to explain how we inte pret ambiguous constructions, we have tried to explain as much as possible linguistically by examination of texts. That is, we want to say not only that a speaker in a given situation intends an utterance literally, we also want to show what he does - what kind of utterances he makes -when he's being literal. This paper hopes to dispel both tuE MisconcepTION THAT METAPHOR IS A PLRILY "STMANTIC" PUENOMENON, and THE MISCONCEPTION THAT MLTAPHOR IS PURELY A LINGUISTIC PHENOMENON.

\section{EFFECTS OF DELETION IN METAPHORING}

Implicit similes and metaphors are highly deleted elliptical constructions. Deletion of the cornpared Predicate, compared Manner item, or comparison-conjoinmg markers, affects their interpretation in many ways:

\subsection{Almost No Effect}

When a phrase is so conventionalized as to have only one interpretation. perhaps has even acquired a secondary usage recorded in the lexicon -.. such as formulas like as parient as Job, as red as a rose, and dead or radical metaphors like in the light of this discussion - then the amount of deletion matters little. We can say with much the same effect:

(45) He's a pig.

(46) He's piggisit.

(47) He's as greedy as a pig.

Similarly, (1) is not much different from (19). ${ }^{9}$

\subsection{Confusion}

The opposite can occur; rather than an interpretation so easy as to be almost unnoticeable, sometimes hear :s stumble across deleted utterances

9 Unless the speaker is comparing her swirm aing or flying swiffly with a gazelle running swiftly, in which case, he would be likely to specify this in surface form. 
so elliptical as to be incomprehensible. Perhaps they lack the necessary experience - to know that as fast as an angry mother hear means very fasi: Or perhaps they lack the necessary knowledge - who Niobe is and that she represents cndless weeping. to understand (48):

(48) She's a Niobe.

Or perhaps they lack the necessary knowledge of language use - children and foreigners unsure of the presuppositions in a language. Or perhaps they misunderstand speaker intention, expecting literal comparison of equation -- the person who replies, "What gazelle? I don"t see any gazelles, just a girl walking down the street!" or "Why did you say you can run faster than a gazelle when you know I can 't measure it?" And sometimes hearers give up from the sheer effort required to interpret complex, embedded constructions most often associated with. but not restricted to, certain kinds of poetry:

(49) Pity, like a naked n'w-born hahe,

Striding the hlass, or heaven's cheruhin, hors'd

Upon the sighless couriers of the air.

Shall blow the horrid dect in every eye,

That tears shall drown the wind.

\subsection{Anthiguty in Form}

Sometimes confusion in interpretation arises from the ambiguity in surface form caused by delction. Surface forms in metaphoring are deceptive: without a comparison marker. metaphors appear to equate: without Assertion and Presupposition information. similes appear to compare rather than attribute with eniphasis. Also, without a comparison marker, metaphors appear to be contradictory: either they must be interpreted as false; or else reinterpreted to handle their markedness. Hence their directness or "orce'.

\subsection{Ambiguity in Meaning}

Deleted compared Predicates or Manner items sreate another kind of ambiguity: a multiplicity of possible meanings. For example, (20) and (21) have a surface form which makes many different PRO-VERBS possible in deep structure:

She BE

quiet/still

as gazelle $\mathrm{BE}$ 


$\begin{array}{lll}\text { She LOOK } & \text { big-eyed/startled } & \text { as gazelle LOOK } \\ \text { Sie ACT } & \text { shy/dainty/graceful } & \text { as gazelle ACT } \\ \text { Sie MOVE } & \text { abrupt/smooth } & \text { as gazelle MOVE } \\ \text { She GO } & \text { swift/tireless } & \text { as gazelle GO } \\ \text { She HAVE } & \text { legsieyes/hroat } & \text { as gazelle HAVE } \\ \text { Sne FEEL } & \text { tiny/helples: } & \text { as gazelle FEEL } \\ \text { She FEEL2 } & \text { smooth/soft/furry } & \text { as gazelle FEEL2 }\end{array}$

She SOUND/TASTE/SMELL/ etc.

resulting in a myriad of possible interpretations. However, this ambiguity may have been deliberately chosen by the speaker. He may want the hearer to accept several rather than merely one of the possible interpretations: some speakers deliberately prolong ambiguities in meaning over the whole discourse. By using an elliptical form of simile, or metaphor, a speaker can mean several things at once; he is less explicit but more allusive. Indeed, metaphor is used preciscly when a speaker does not care to nor need to be explicit --. if, when he describes a girl, he does not particularly care whether the hearer learns that she runs swiftly, just that she is delicate, graceful, shy, and also swift, he will use implicit rather than explicit simile form. In this way, metaphoring is a sHorTcur to multiple meaning; to say explicitly what a metaphor alludes to would take more than a few separate expljcit similes. The price of the shortcut for the speaker is loss of control of whicll of the possible mulciple meanings hearers may select, though convention will predispose them to certain ones.

\subsection{Active Imerpretation}

Deletion enhances the power of the hearer; as the speaker is less explicit, the hearer nust be more active. He must search for the unstated compared aspe ts, resolve feature contradiction, decide which of several interpretatic ns to accept, resolve the ambiguities of surface form, and with metaphors, reinterpret the structure if he is not to take it as literally false. With metaphoring, the hearer may choose - to interpret or block interpretation; to interpret literally or nonliterally; to select one or several possible metaphorical interpretations.

\subsection{Economy of Expression}

Finally, deletion creates a 'compression of meaning' found in meta- 
phoring, an economy of expression. However, this brevity and efficiency can be achieved in two different ways, by 'shortcuts' and by 'freshcuts'.

\section{REASONS FOR METAPHORING: SHORTCUTS AND FRESHCUTS}

Deletion in simile and metaphor constructions creates effects which speakers use deliberately to convey meaning. These reasons fall into two basic categories: SHORTCUTS and FRFSHCUTS to language expression formulas or original sayings. They either save time and thought or else demand time and thought; they either emphasize the compared quality, or else draw attention to the second Argument, as in a Homeric simile. Shortcuts offer brevity and efficiency; freshcuts, originality and attention.

First, however, we wish to restate that all metaphoring is economical, that the process itseif is a shortcut to meaning. Speakers use metaphor whenever explaining something literally would take too long. be too complex an analysis, or else would be impossible. Metaphoring can enable us to explain a complex process by analogy to a more familiar, simpler model; to present a world-view, a way of seeing, without having to argue is merits point by point; to suggest and connote attitudes without having to state them directly; to hint at the ineffable; or to describe a totally new experience or phenomenon. Secondly, all metaphoring uses formulas, patterns of deletion and processes like Personification and Synesthesia, but this is quite different from the utterance itself being a formula.

\subsection{Shortcuts}

Shortcuts are easy to identify by filling in the blanks:

as dead as a..... doornal

as vain as a...... peacoch/primadonna

he's a pig means he's...... greedy

he has an...... iron...... will

Etc.

The Argument of the Presupposition, $\mathrm{S}_{2}$ in the deep structure, is equated with its Predicate by habitual use, to the exclusion of all other Predicates for that Argument. Thus, Job comes to represent patience rather than bad luck, and Niobe, weeping rather than fertile motherhood. Allusion, 
epithet, and metonymy are three familiar figures for shortcuts, though they can be used for 'freshcuts' as well.

Conventionalized similes and metaphors are used for several reasons: (1) they are easy to think of, being familiar; (2) being familiar, they are likely to be clcar to the hearer, so that the speaker relinquishes a minimum of control over interpretation: (3) being clear, they are not likely to distract the hearer's attention from the topic of the discourse, and thus they can be used purcly for emphasis. Dead as a doomail is really dead, and if a hearer gets distracted into thinking about doomails, the speaker has failed in his intentions. These formulas must lose most of their meaning. becoming almost all emphasis, to be successful shorteuts. Eventually they reach the status of idions or dead metaphor and end up in a dictionary of idioms and similes.

\subsection{Freshcuts}

A.t the other end of the continuum are fresheuts, also casy to identify because we carnot fill in the blanks; we would not have thought of them. As soon as Dylan Thomats writes, worlds hang from the trees, we are struck by his freshness of vision. Speakers use freshcuts to gain attention: attention to their originality, their wit. their verbal skill, their particular ways of seeing and believing. Fresheuts force the hearer to stop, notice, and reinterpret, since the uterance is new, though the pattern will be pre-coded in the language. Freshcuts reveal the speaker's personality and unique mind: critics often study a man through his imagery (Spurgeon, 1935; Rugof, 1939).

Freshcuts arise to explain new experience, particularly new ways of seeing and feeling. Paranoia can be expressed by Animating and Personifying the world around us: the desk squats in wait; the furniture listens; the computer is angry. Less extremely, the lake is angry and sullen to those who can't swim; if the gate won't close, it's being unreasonable: if the city sprawls, it's getting out of hand: and the ar sabotages every goddam vacation we get. Similarly, metonymy can be used to express the notion of a split self, and to disclaim responsibility for our actions:

My mind is patriotic, but my stomach is hungry.

My foot kicked over the vase, I didn't.

Silence murdered this man.

Through the use of connotation, freshcuts present attitudes and points of view obliquely. Saying that she has a plastic smile conveys the con- 
ventional notion of 'fake', but also the connotations of 'man-madc', 'superficial'. 'mass-produced', 'cheap', 'unnatural', etc. However, this process can function more subtly. For example, in the Dr. Seuss story, "Bartholomew and the OObleck", a consistent series of similes used to describe this nonsense item convey a set of secondary qualities: first the oobleck comes down as big as raisins, then as big as plums, then as big as grapefruit - but not as big as quarters or barketballs. indicating several secondary characteristics of oobleck as 'chewable". "edible', 'fruity in taste'. and 'round or drop-shaped". So when the King's guard tries to eat some, we are no: surprised to find it more like bubblegum than anything else.

Freshcuts can also force a new way of seeing, as a heuristic tool for invention: Synectics exercise (Gordon. 1961) "make the familiar strange" and the "strange familiar"; for example, "imagine you are a coil or spring" or "suppose a can opener worked tike a clam". And freshcuts can create humor aut of the unexpected and incongruous; one pattern is to take an unhappy simile and modify it - as light as a toad becones as light as a toad filled with helitm, and (16) becomes (17t or (18).

Finally, speakers, whether scientific or religious, resort to freshcuts to communicate the nontangible and ineflable. Sometimes the freshcut is an image, sometimes a whole story or parable. but in each case it forces the hearer to become involved in active interpretation, to find meanings, and accept or reject these as a way of living.

\section{MFTAPHORING; AS SPHFCH ACT}

We have shown earlier that metaphor cannot be isolated in a single word or phrase; similarly, neither can mctuplor be isolated in the single sentence. Since similes ard metuphors in isolation are ambiguous constructions, such as (19) through (27). such study of metaphoring apart from context can only indicate the presence of comparison markers and feature contradiction, hypothesize contexts, ard supply poteNTIAL. literal, potential anomalous, and potential metaphorical interpretations. Only rarely does metaphoring occur within the confines of a single sentence; it is much more of a discourse and genre phenomenon, or, as Austin puts it (1962:138), "what we havc to study is not the sentence but the issuing of an utterance in a speech situation", or "the total speech act". 


\subsection{Context and Referen?}

Metaphoring cannot exist independent of context and referent. only metaphorical patterns and potential metaphorical interpretations. Context and referent can disambiguatc utterances like (19) through (27). However, let's examine what would seem to be an obvious metaphorical phrase rather than an ambiguous one to make this point clear: blossoms of smoke. Unfortunately, without considering the total spech act, we can not know whether the phrase refers to:

(a) grey blossoms

(b) billowing smoke

(c) flowers on a smoke tree

(d) nothing at all

(e) growing feelings of emptiness

(f) all or none of these.

Again, is there a metaphor here? If so, which one?

\subsection{Speaker and Hearer}

Similarly, metaphoring cannot exist independent of speaker sind hearer, only attempts and possible interpretations. Metaphoring is an interpretive act by both speaker and hearer.

When a child still learning the language utters one of the following, he does not intend it as metaphor. but as literal though analogical statement:

(50) I broke off a leaf and now the tree's bleeding.

(51) (of an excavation) Hey, they're building a hole!

The parents' delight is not so much in the näivete of such utterances, since they are not equally enraptured with other analogical utterances like $I$ goed home and Itch my back, but in the metaphorical interpretation THEY, the parents, give such utterances, what is often called a child's 'freshness of vision'. Thus, with (50), the child probably still considers tree as [+Animate] like animals, and for him, the utterance contains no feature contradiction. Later, or perhaps immediately, he learns the metalingual information:

'Trees don't bleed; they don't have blood, but sap; and the sap leaks." 
Then, being more sophisticated, he realizes that $(50)$ is a mintike. $n$ no longer utters it, since he is busy mastering literal communic ati i.: In contrast, the parents are likely to interpret $(50)$ quite ififere ily perhaps as Animation of tree, but more probably as Objecilitciin (De-animation of bleed): "tree leaks sap like blood". Thus, how it "ve", utterance of the $[\mathrm{A} \sim \mathrm{P}]$ patte $i$ is interpreted depends on both sp $k$ e and hearer intention and speaker and hearer knowledge of the la ly:ta ... and culture.

Liniting linguistic analysis to single sentences, or an examinati. a the 'text', supposedly avoids the "intentional fallacy" (Wimsitl ard Brooks, 1957). However, the intentional fallacy arises, NOT IROM if :SIDERING SPEAKER INTENTION AS PART OF THE SPEECH ACT, BUT : NOT CONSIDERING THE TOTAL SPEECH ACT -- a person outside the s:se act hypothesizes a speaker intention which may or may not have ixen the case. Simply because speaker intention is hard to ascertitin -- I can know a speaker's intention only if I am the speaker, or if the speaker tells me (and he might be lying or putting me on) - does not me: in that it can be ignored in studying the process of metaphoring. Indeed, ignoring the notion of intention makes defining and using the terms LITrk $\mathrm{N}$, and NONLITERAL impossible; they cannot be defined outside the total speech act, since. though they may be predicated of sentences, these terms PRESUPPOSE a speaker or hearer with that particular intention.

\subsection{Speech Act}

Metaphoring is itself a speech act very much like stating or commar ding: expressing, suggesting, even imposing a viewpoint counter to fact by means of an Assertion conjoined to a Presupposition by a comparison marker, each of which may be partially or wholly absent in the actua! utterance, or surface form.

Metaphor is one of Austin's 'masqueraders', and so is simile; metaphors masquerade as equative, identifying constructions which are false or 'deviant'; similes masquerade as comparisons of qualities which can be either measured and verified or else checked against actual language use. But the effec: of conjoining a Presupposition to an Assertion is to attribute and emphasize a quality or qualities not usually associated with a given item. Metaphoring, because it is both factual statement AND metalingual statement, is in combination, NEITHER. Since it is 10 This is not to say that children do not master certain types of metaphoring quite early; they are quite expert at hurling epithets like Pig! and Stinky garbagecan! 
only partly Assertion, it cannot be literal; since it is only partly Presupposition, it cannot be a definition. Metaphoring does not 'describe' or 'report' or 'constate' anything but what the speaker creates momentarily as a counterfactual reality; thus, metaphors are neither true nor false, only happy or unhappy. Metaphor is an action which is more than SAYING something: it is fabricating another 'reality', a world suspended between a posteriori and a priori. Thus metaphor IMPOSEs a way of seeing, feeling, connecting, and judging: it forces the speaker's unique and momentary 'world-creating' and 'contrary-to-fact' perspective on the hearer.

Much metaphoring occurs within discourse which indicates a truthsuspending mode, by such verbs as imagine, helie've, dream, suppose, etc., and certain uses of if. But others appear as direct statements, yet they function very much like weak commands, suggestions to see or feel in a certain way, as both locutionary and illocutionary acts. It is as if a speaker were saying. "I urge you to see it thus", "I suggest you see it thus", "I create it thus", "I assert it thus"; or "sce it this way, feel this way, to understand me".

\subsection{Levels of Metaphoring}

We can distinguish three levels of illocutionary force in metaphoring, what might te called:

(a) Suppositrves - used playfully, not scriously, for fun and for explanation (17) (18) (36)

(b) Perceptives or suggesnives - used mainly by an observer or everyday speaker to explain his feelings and viewpoints (1) (23) (27) (34) (35)

(c) IMPOSITIVEs - used by poet and propagandist to convey his message and bias by creating a new and unforgettable way of seeing and feeling towards a subject (25) (27a) (49)

Only with impositives does a question of belief arise; with the first two types the speaker is not urging the hearer to BELIEVE what he says is true, nor necessarily to AGREE with him, but merely to ACCEPT that his utterances have value - either useful in communicating concepts and feelings, or else of merit as an individual's self-expression. With the third type, the speaker hopes to persuade the hearer to adopt his viewpoint. The suggestive speaker uses existing metaphor, ranging from the relativaly 
unfamiliar to the unnoticed, and common pre-coded patterns; the im. positive speaker creates new metaphor, or uses existing metaphor in new ways, and may create new patterns and neologisms (31).

\subsection{Speech Act Markers}

Metaphoring, unlike performatives, is not marked by a set class of verbs, such as PROMISE or URGE. Certain verbs indicate truth-suspending or 'be-in-appearance-only' modes, but these are not necessary nor sufficient markers for metaphoring. However, the two types of speech acts are similar in that (Austin, 1962:5-11):

(a) uttering them is not enough;

(b) but uttering is the leading incident;

(c) the circumstances must be appropriate; and

(d) the speaker and hearer perform certain mental actions.

An utterance is not a metaphor, only a potential metaphor, an attempted metaphor. Uttering is the leading incident of metaphorical interpretation. Circumstances must be appropriate; for example. the genre and discourse for considering (21) a metaphor might be "ordinary. casual conversation about the topic, Mary Jones". Then, the speaker must intend the utterance as metaphor, and the hearer must interpret it as metaphor. Metaphoring, then, is different from ethical speech (ought), but closely related to hypothetical speech (can, would, if). Let us examine further how Austin's criteria for speech acts apply to metaphoring (1962: 36-39).

\subsection{Speech Act Criteria}

If we accept metaphoring as a type of speech act which has both locutionary and illocutionary force, then we can apply Austin's felicit! criteria, or happiness conditions, to this act:

(A.1) There must exist AN ACCEPTED CONVENTIONAL PROCEDURE having a certain conventional effect, that procedure to include the uttering of certain words by certain persons in certain ci cumstances.

Three such conventional procedures exist: GENRES; CUL URAL ASSOCIATIONS OR FORMULAS; and PRE-CODED LANGUAGE PROCESSIS.

Genres, such as poetry, fable, parable, fairy tale, chiliren's story, advertisement, myth, dream, tall tale, and so on, all are well-known 
conventional procedures for nonliteral expression; metaphoring occurs unmarked WITuIN such genres, since genre-markers, such as once upon a time ..., cue hearers not to expect literalness.

Cultural associations or formulaic phrases, such as allusion, epithet. emolem, and cliché, are also accepted conventional procedures for nonliteral expression. A hearer may not know who Niobe is, but he will know that in (48) the speaker means Niobe-as-a-type, not a Niobedown-the-street, and that she represents some quality, even though he does not know which quality.

Finally, pre-coded language processes are essential for metaphoring, though not sufficient. Some of these processes are particular to metaphoring, st th as Synesthesia and Personification; out others function also as ordinary language processes, part of the creative aspect of a language. such as Spatialization and Instrumentification, noted by Fillmore (1968), Weinreich, and Lambert (1969). Many instances of IITPRAI. USF of these pre-coded processes have been starred by linguists:

(52) I hit him with John. (not Comitative)

(53) A fly crawled on John.

(54) Give me some more pillow:

(55) I broke the stratiberry in swo. (a china one1

(56) She swam through the intersection. (in Venice)

However, this narrowing of focus by transformationalists to only the most familiar and banal of isolated sentences has meant, ironically, ignoring the many creative aspects of language, its flexibility of expression. and the whole series of pre-coded processes a speaker has at his disposal. Fillmore discusses Instrumentification - using an object or person as an instrument, as in (52): Spatialization -- using an object or person as a location, as in (53); and Materialization -- using an object or person as mass or material, as in (54), in the context of a case grammar. Weinreich, however, explores their function in a transformational framework. We have fitted these pre-coded processes into the more general framework of comparison-conjoining in deep structure, as in (23) and (27): both are ambiguous metaphors; more specifically, (23) is the pre-coded process of Animalization, as is (21), while (27) is either the pre-coded process of Personification or of Objectification.

(A.2) The particular PERSONS AND CIRCUMSTANCES IN A GIVEN CASE MUST BE APPROPRIATE for the invocation of the particular procedure invoked. 
The right circumstances for metaphoring can be stated for each particular case, but also for more general types, such as Personification (27) or Arimalization (21) and (23). For example. for one kind of pers s nification, the speaker might be parent or children's author; the hearer, children; the time, bedtime; the genre, fairy tale. Then if tables start to dance. no one is startled.

(B.1) The procedure must be executed by all participants CoRrfCTLY. The speaker must create a proper metapherical utterance: one that is an Assertion conjoined to a Presupposition by comparison, one that is about the topic of conversation, etc. And the hearer must interpret this utterance, not as litcral comparison nor as false litcral cquation, but as metaphor.

(B.2) The procedure must be executed by all participants COMr.fetely.

For example, the speaker must finish his utterance:

(57) He is as vain as...uh ...uh...a peracosk.

And the hearer must be listening. And so on.

(Г.1) Where the procedure is designed for use by persons having CERTAIN THOUGHTS, FLELINGS, OR INTENTIONS, or for the inauguration of certain consequential conduct on the part of any participant, then a person participating in and so invoking the procedure must in fact have those thoughts, feelings, or intentions, and the PARTICIPANTS MUST INTEND SO TO CONDUCT THEMSELVES.

For example, the speaker must istend to compare nonliterally, rather than lic, joke. compare literally. make up nonsense, etc. Similarly, hearers must interpret nonliterally, rather than insist on a procedure not intended by the speaker, such as literal comparison. That is, speaker and hearer intention is crucial.

(Г.2) The persons must so CONDUCT THEMSELVES SUBSE QueNILY.

The hearer cannot begin arguing with the speaker about the truth of his utterance; nor can he accept the utterance at first and then later go around telling everyone that the speaker is 'crazy' because he identified a girl as a gazelle. Nor can the speaker expect the hearer to BeLieve what he has said; or if the hearer DOEs believe the hearer and ake him literally, then the speaker cannot chuckle and think he has "put one over" on the hearer. 


\subsection{What Can Go Wrong With Metaphoring}

With these criteria of Austin's appliet to metaphoring, we can now investigate more fully what can go wrong with the speech act, rather than how a 'metaphor' (a sentence) can be 'deviant'. First, metaphoring must fit criteria established in gent ral for speech act. That is, the following must appiy:

- the speaker and hearer kno $*$ the language

- the speaker and hearer are not asleep, blind, deaf, dumb, insare. etc.

- the speaker believes the hearer is not asleep ... etc.

- the speaker is not ir tending falsehood, lies, ... etc.

- the hearer is not expecting falschood, lies, ... etc.

- the speaker is trying to communicate something to someone

- the hearer assumes the speaker is trying to communicate something to $\mathrm{him}$

- the hearer tries to interpret, tries to make sense of what the speaker says

- and other items of 'good faith'

However, more specifically for metaphoring, we can examine these:

\section{(A.1.) NON-PLAYS}

We have examples of what Austin calls 'non-plays' when a hearer refuses to accept or acknowledge a conventional procedure. Such is literalmindedness; the hearer refuses to enter in, refuses to accept such pre-coded processes as Animation, blocks interpretation, gets angry af the speaker, and so on. This hearer hates poetry, considers fiction a waste of time (as well as small talk), reads only for 'information', and finds it disturhing that Jesus spoke about wineskins and bridgerooms instead of saying right out what he meant. When this hearer becomes speaker, he wastes no words; he is serious, direct, and often dull. More often, he is at a loss for words, since he recognizes only a limited number of mechanisms for saying what he is thinking and feeling. As a result, he restricts his discourse to tangible or observable phenomena, and remains inarticulate the rest of the time.

\section{(A.2) Misapplications}

There are 'right circumstances' for general types of metaphoring: Personification is inappropriate, for example, in scientific reports, as is body-part Metonymy. And there are 'right circumstances' for specific 
instances of metaphoring as well, what we have been calling 'context and reference'. Thus, one set of 'right circumstances" for uttering (21) might be: speaker and hearer are talking on the way home from work about the relative merits of the girls in the office; immediate topic is Mary Jones, not gazelles: other Animalization metaphors might be expected within the same conversation. such as she's a cow, since the pattern has already been established for this discourse.

However, suppose the circumstances are different: speaker and hearer are at the zoo, talking about deer. impala, and gazelles. If the speaker now says without pointing, she's a gazelle, the hearer is likely to be genuinely confused. We usually talk about animals in general by $i t$, unless their sex happens to be relevant to the topic; we don't usually switch topics in the middle of a discourse without some karning. So the hearer will not know whether the speaker is referring to a particular four-legged 700 animal which he has identified as both a gazelle and a female, or to a nearty girl walking towards them. Thus Misinierpretations arise from Misapplications.

\section{(B.1.) Flaws}

We have already discussed flawed or unhappy similes, stich as (9) through (14) and (16), which violate one of the two criteria the correct $[A \sim$ P] form: a cerrect Presupposition. There are also flaws in comparison-conjoining. such as (2) through (5). However, besijes speaker flaws in creating metaphorical utterances, we also have hearer faws in interpretation. He may not be paying attention enough to calch a switch in topic from girl to gazelle, or a switch from literal comparison to metaphorical epithet. Or he may lack knowledge: he thinks all rocks are green, having seen only green ones; or he does not know that elegies are poems about the death of someone, and are usually sad.

\section{(B.2.) HitchES}

An incomplete act of metaphoring can occur for many reasons; two instances were just given: the speaker must finish, and the hearer must be listening. Also, the hearer must finish giving the utterance an interpretation, and not get sidetracked.

\section{(Г.1.) INSINCERITIES}

Speakers, when metaphoring, must intend to attribute and emphasize, rather than compare literally or equate. They cannot be liars, jokers, madmen, or children or foreigners intending to be literal. Similarly, hearers cannot be literalists or poetry-haters. Indeed, literalist $=$ would say 
that a speaker is being INSINCERE if he moves from uttering (32) to the more deleted forms (58) and (59):

(58) I feel worms crawling in my bones.

(59) Worms are crawling in my bones.

since "worms can't crawl IN BONEs" - presuppositional knowledge. However, insincerity must be judged in terms of intention; if performance matches intention, then a speaker cannot be judged insincere. If a speaker utters (58) or (59) in reply to the question, "What's wrong with you?", we cannot. consider him insincere simply because he replies metaphorically, rather than trying to describe his sensation in medical terminology. Nor can he be considered insincere because he extends a Presupposition temporarily, if this is what he intends to do to convey his feelings; he is not insincere if he knows bones are solid and cannot be crawled in, $y$ t nevertheless utters (58) or (59); he is simply using language nonliterally in an accepted, pre-coded pattern: Spatialization. Thus, we do not consider metaphoring itself an 'insincere' speech aci.

\section{(T.2) Rejections}

Finally, hearers, because of false expectations, cannot subsequently reject a speaker's discourse. Some examples have just been given; another is, if a hearer took a speaker's metaphoring as literal directions and them became disgusted when they did not work.

In the majority of this paper, we have focused on pre-coded conventions (A.1), circumstances (A.2), intention ( $\Gamma .1)$, and particularly, FlaWS IN PROCEDURE (B. 1, 2). Since circumstances and intention can disambiguate simile from literal comparison and metaphor from partial definition; and flaws in procedure can explain why certain constructions are 'unhappy' then utterances like (28) and (60) are no longer mysteriously odd:

(60) Triangularity drinks coke.

This utterance violates condition (B.1.A) - we are hard pressed to find a compared Predicate in the deep structure:

$$
\text { [triangularity } \mathrm{BE} \mathrm{X}] \simeq[\mathrm{ANIMATE} \text { drink coke] }
$$

UNLESs circumstances, (A.2), inform us that Triangularity is the nickname for a child or dog; or UNI.ESs speaker intention, ( $\Gamma .1)$, tells us that (28) and $(60)$ are supposed to be uninterpretable, and were created specifically to illustrate anomalous constructions. 
Studying metaphoring as process. as a type of speech act with both locutionary and illocutionary force, rather than as an isolated linguistic object which is "deviant', enables us to explain such failures and odditics in communication as $(60)$. It also enables us to explain how succestut metaphoring occurs and is given interpretations. Despite the fact that Austin considers metaphor "hollow". "parasitic". "not serious". and "not normal use" (1962: 104) ... and Searle as well $(1969: 78)^{11} \ldots$ by further studying suppositive. suggestive. and impositive metaphoring, we can begin to EXPLAN the "force' or 'tension' or 'power' or 'persuasise impact' or "shock value' or "plurisignation" that so many critics mereiy IDENTIY when they write about metaphor.

University of Michigan

\section{RLFERENCIS}

Austin, 3. L.

1962 How to bo Thimgs ith Words (Cambridge: Harvard University Prews).

Bickerton. Derek

1969 "Prolegomena to a Linguistic Therry of Metaphor", Foundarions of Languaze j. 34-52.

Black, Max

1962 Mode's and Moraphers: Studies in Language and Philesophy (lthate: : Corneit University Press).

Brooke-Rose. Christine

1958 A Grammar of Mfolapher (London: Secker and Warburg).

Chomsky, Noam

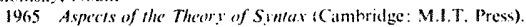

Fillmore, Charles

1968 "The Case for Case", in: E. Ba ha and R. Harms (eds.), Eniversals in Lingnistic Theory (New York: Holt, Rhinghart, and Winston).

1969 "Types of Lexical Information". in: F. Kiefer, (ed.). Studies in S.max and Simantics (Dordrecht: Rcidcl).

Gordon, J. J.

1961 Synetios: The Derelopment of Crative Cafacity (New York: llarper and Row).

11 Philosophers seem to be as pejorative as linguists ahout metaphoring (metaphor is deviant, abnormal, mistaken, nonsensical trivial, derivative, parasitic, non-serious, accidental, etc.) which may indicate their inability to deal with the phenomenon. Austin even states that with metaphors like go and carch a falling star, that "no attempt is made at a standard perlocutionary act, no attempt to make you do anything, as Walt Whitman does not seriously incite the eagle of liberiy to soar". Yet the speaker Dots attempt to make the hearer do something -- not to train eagles to fly or to try and catch stars, but to see the world in a new way, to reinterpret the utterance nonliterally. is long as metaphoring is not considered 'nornal use'. linguists and philosophers must dichotomize utterances into normal and nonnormal categories, and distinguish between the two - which means assuming th t such a norm exists. This narrow view leads to ignoring all kinds of nonliteral speech acts, and an incomplete theory of ordinary language use. 
Isenberg, Arnold

1963 "On Defining Metaphor", foumal of Philesuph. LX, 609-22.

Lakof, George:

1971 "Presupposition and Relative Well-Formedness", in: Steinberg and Jakobovits (eds.), Somanics: An Interdisciplinary Racaler in Philosaphy, Linguistics, and Psycholog. (Cambridge: Cambridge University Press).

Lambert, Dorothy

1969 "The Semantic Syntax of Metaphor: A Casc Grammar Analysis" (unnublished Ph, D. dissertition: Ann Arbor).

1970 "Some Happiness Conditions for Explicit Similes", Papers in Lingruistics $2: 2,359-79$.

Levin, Samuel

1964 "Poetry and Grammaticaltess", in. H. G. Lunt (ed.). Procesdings of the IXth Internationul Congress of Linguists (The Hague: Mouton).

McCawley, James

1968 "The Rolc of Semantics in a Grammar", in: Bach and Harms, Unitersals in Linguistic Theory (New York: Holt, Rhinehart, and Winston).

Margolis, J.

1957 "Notes on the Logic of Simile, Metaphor, and Analogy", Americun Specth $\mathrm{X} \times \times 11186-89$.

Mathews, J. R.

1971 "Concerning * 'Linguistic Theory" of Metaphor", Fonudations of Language" 7, 413-25.

Reddy, Michael

1969 "A Semantic Approach to Metaphor", in: Bimick et al. (eds.), Procecdings of the Fifth Regional Mereting of the Chicago Linguistic Society.

Richards. 1. 1

1936 The Philow phy of Rhetomic (New York: Oxford University Press)

Rugoff M. A.

1939 Donne s Imagery: A Study in Creative Sources (New York: Corporate Press).

Scarle, John

1969 Speech Acts (London: Cambridge University Press).

Spurgeon, C. F. E.

1935 Shakespeare's imagery and What It Tells Us (New York: Macmillan).

Torrance, E. P., and Myers

1965 Can Youl lmagine? (Boston: Ginn).

Weinreich, Uriel

1965 "Expiorations in Semantic Theory", in: T. Sebeok (ed.), Current Trends in Linguistics III (The Hague: Mouton).

Wheelwright, Philip

1962 Metaphor and Reality (Bloomington: Indiana University Press).

Wimsatt, W. K., and Brooks

1957 Litirary Criticism: A Shor History (New York: Knopf).

Dorothy $\mathbf{L}$. Mack is assistant professor in the department of Humanities of the University of Michigan at Ann Arbor. She is interested in the theory of metaphor, engineering and education. Among her main publications are: The Semantic Symtax of Metaphor: A Case Grammar Analysis (Ph. D. University of Michigan 1969, to be published by Mouton). "Some Happiness Conditions for Explicit Similes Papers in Linguistirs (1970), "Metaphorical Ambiguities", in: Meaning: A Common Ground between Linguistics and Literature, University of N. Iowa Conference Proceedings, april, 1974; "Current Misconcepetions about Metaphoring, ibid.

[received: August, 1972] 